\title{
Evaluation of Carotid Intima Media Thickness and Resistive Index by High Resolution Ultrasound in Hypertensive Patients and Normotensive Subjects -A Comparative Study
}

\section{P. SATHISH PRABHU, VENKATRAMAN INDIRAN, PRABAKARAN MADURAIMUTHU}

\section{ABSTRACT}

Introduction: Intima media thickness (IMT) and Resistive index (RI)of common carotid artery are known to reflect the whole body vascular system atherosclerosis. Hypertension is one of the major risk factors for atherosclerosis. There are limited numbers of studies assessing these parameters in hypertensive patients in Indian population.

Aim: To assess and compare common carotid artery (CCA) Intima-media thickness (IMT) and associated Resistive index (RI) changes in hypertensive patients and normotensive subjects using high frequency ultrasound and colour Doppler.

Materials and Methods: Total of hundred patients were studied over a period of one year. Out of hundred, sixty were hypertensives (less than two years duration) and forty were normotensives. Gray scale and duplex sonography of carotid arteries were performed on both sides using high frequency transducer. IMT measurement, color flow mapping and $\mathrm{RI}$ measurement were done in both distal
CCA. The results obtained in hypertensive patients were compared with that of normotensives.

Results: Common carotid artery IMT in normotensives was $0.50 \mathrm{~mm}$ and $0.49 \mathrm{~mm}$ for the right and left sides respectively. $\mathrm{RI}$ in normotensives was 0.55 on both the sides. IMT in hypertensives was $0.96 \mathrm{~mm}$ and $0.97 \mathrm{~mm}$ for right and left sides respectively. RI in hypertensives was 0.67 on both the sides. So, Intima media thickness and Resistive index in hypertensives were significantly increased in hypertensives as compared to normotensives.

Conclusion: Hypertension is a major risk factor for atherosclerosis. Changes in IMT as a morphological parameter and $\mathrm{RI}$ as a hemodynamic parameter may aid in early diagnosis of atherosclerosis of the vascular system. These parameters can be assessed safely, easily, accurately and in an inexpensive way using high frequency ultrasound and Doppler. Our study revealed that IMT and RI of CCA were significantly increased in all hypertensive patients compared with normotensives and it is ideal to assess both IMT and RI together.

Keywords: Atherosclerosis, Carotid Doppler, Ultrasonography

\section{INTRODUCTION}

Hypertension is an important cause of serious cardiovascular diseases and premature mortality from such diseases [1]. Hypertension increases the risk of stroke, coronary artery disease and peripheral arterial disease by twothree fold with the risk being proportional to the severity of hypertension [2]. Increase in Intima-media thickness (IMT) of an artery has been used as a surrogate marker of the early atherosclerotic process [3]. Atherosclerotic process starts in the carotids approximately at the same time as in aorta, actually preceding plaque occurrence in coronary arteries. Carotid atherosclerosis significantly correlates with extent of coronary artery atherosclerosis suggesting that increased IMT not only reflects the local morphological alterations in the carotid arteries but also corresponds to generalized atherosclerosis [4]. Non invasive techniques such as high resolution ultrasound imaging allow the measurement of combined intima and media thickness [5].

Though, it is known that atherosclerosis reduces the distensibility of carotid arteries, their assessment is usually 
difficult. In contrast, the Resistive index (RI) is a hemodynamic parameter that is easily determined by Doppler sonography basically reflecting the vascular resistance, which in turn depends on distensibility of the vessel. So, Intima media thickness (IMT) and Resistive index (RI) are complementary to each other in assessing the atherosclerosis of vascular system [6]. According to many studies IMT as a morphological parameter and $\mathrm{Rl}$ as a hemodynamic parameter are surrogate markers of atherosclerosis [6]. However, there are limited numbers of Indian studies using these parameters to assess atherosclerosis in hypertensives and comparing them with normotensives.

\section{MATERIALS AND METHODS}

Data for the study was collected from patients with clinical diagnosis of systemic hypertension of duration less than two years, referred to Department of Radiodiagnosis at Sree Balaji Medical College and Hospital, Chennai for carotid Doppler study. All the included patients were under medical treatment with anti hypertensives. Patients with diabetes and hypercholesterolemia were excluded by measuring blood sugar and lipid levels. Patients or subjects with confounding factors like alcohol intake and smoking were excluded from the study. The ethics committee of our institute approved this prospective case control study and an informed consent was taken from all the patients (cases) as well as subjects (controls) included in the study.

The normotensive subjects (controls) were students, patient's relatives and clinical staff. The study was performed for the period of one year from May 2012 to May 2013. No financial burden was placed on the patient.

Total number of subjects selected for the study was 105 with 65 hypertensive patients aged between 35- 55 years (cases) and 40 normotensives subjects (controls) of same age group and sex. Out of 65 hypertensives bilateral CCA measurements was possible in only 60 patients. 5 patients were excluded; three due to enlarged thyroid gland causing compression of CCA and 2 cases because of low bifurcation of CCA. Finally total number of subjects studied was 100, which includes 60 hypertensives (cases) and 40 normotensive subjects (controls).

We used SIEMENS Acuson 2000 with 7.5-10 MHZ linear array transducer to image all the patients. After explaining the procedure to the patient, the patient was made to lie in supine position and chest being elevated with a pillow and the head being turned to the opposite side of the carotid artery under examination. The CCA was examined in transverse and longitudinal view [Table/Fig-1] starting from origin to its bifurcation. The IMT was defined as the distance between the leading edge of the lumen-intima echo and the leading edge of the media adventitia echo. IMT was measured at
0.5-1 cm proximal to carotid bulb on the right as well as left side. Colour Doppler imaging was done for both CCA at 0.5-1 cm proximal to carotid bulb with frequency of 3.5- 5 $\mathrm{MHz}$. Maximum Doppler angle of $60^{\circ}$ with a sampling volume of approximately half of the vascular diameter was used. The maximum systolic and minimum diastolic flow rates were determined and Resistive index (RI) was calculated automatically in a cycle by means of inbuilt software. All the examinations were done by two examiners independently and the IMT and RI values were obtained twice by each examiner. The values were analysed to derive the mean value for RI and IMT for all cases and controls. Chi-square test has been used to find the significance of proportions of hypertensives in different age groups. Student't' test has been used to find the significance of Blood Pressure parameters and Intima media thickness (IMT) between normotensives and hypertensives. Mann Whitney $U$ test has been used to find the significance of Resistive index between normotensive and hypertensives.

\section{RESULTS}

The mean age of the 60 cases included in our study was 43.5 years and mean age of the controls was 44 years. Gender distribution was about 60:40 (Male: female ratio) in normotensive group and about 53:47 (Male: female ratio) in hypertensive group [Table/Fig-2]. Both hypertensive and normotensive groups were nearly proportionately distributed in all age groups and both sexes [Table/Fig-3]. Mean systolic and diastolic pressure in normotensive subjects was 111/ 75 $\mathrm{mm} \mathrm{Hg}$. Mean systolic and diastolic pressure in hypertensive patients was 151/ $98 \mathrm{~mm} \mathrm{Hg}$. [Table/Fig-4,5] shows the mean IMT and RI measurement of right side, left side and combined values of both sides in hypertensives and in normotensives. The IMT and RI in hypertensive cases were significantly higher on both sides. Mean combined IMT was

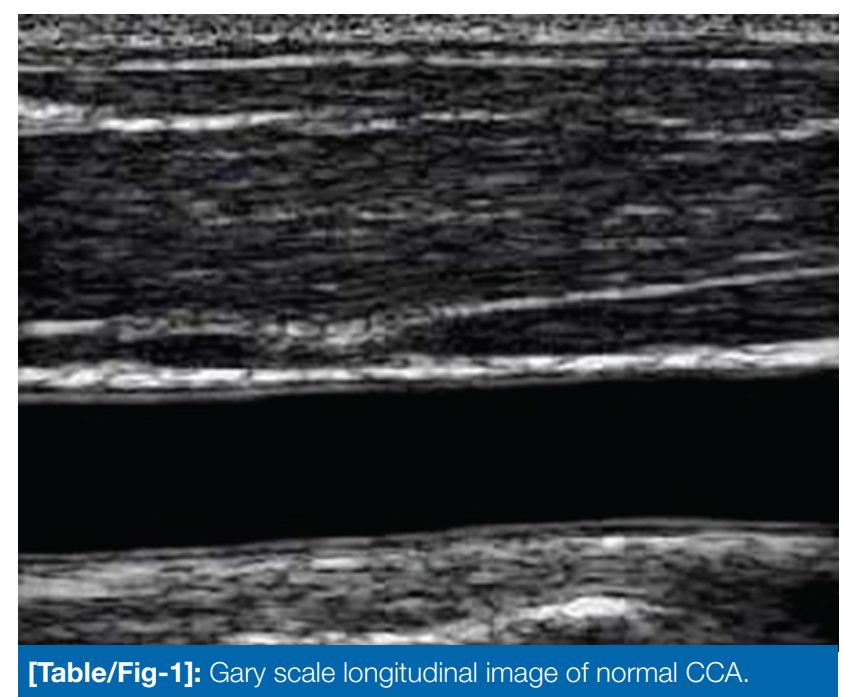




\begin{tabular}{|c|c|c|c|}
\hline $\begin{array}{l}\text { Demographic } \\
\text { characteristics }\end{array}$ & Normotensive & Hypertensive & p value \\
\hline Age & $43.00 \pm 5.26$ & $44.32 \pm 4.78$ & 0.198 \\
\hline Sex & $\begin{array}{c}\text { Female- } 40.0 \% \\
\text { Male- } 60.0 \%\end{array}$ & $\begin{array}{c}\text { Female- } 46.7 \% \\
\text { Male- } 53.3 \%\end{array}$ & $>0.05$ \\
\hline SBP & $111.75 \pm 6.84$ & $151.38 \pm 4.68$ & $<0.01$ \\
\hline DBP & $75.85 \pm 5.01$ & $98.27 \pm 2.91$ & $<0.01$ \\
\hline
\end{tabular}

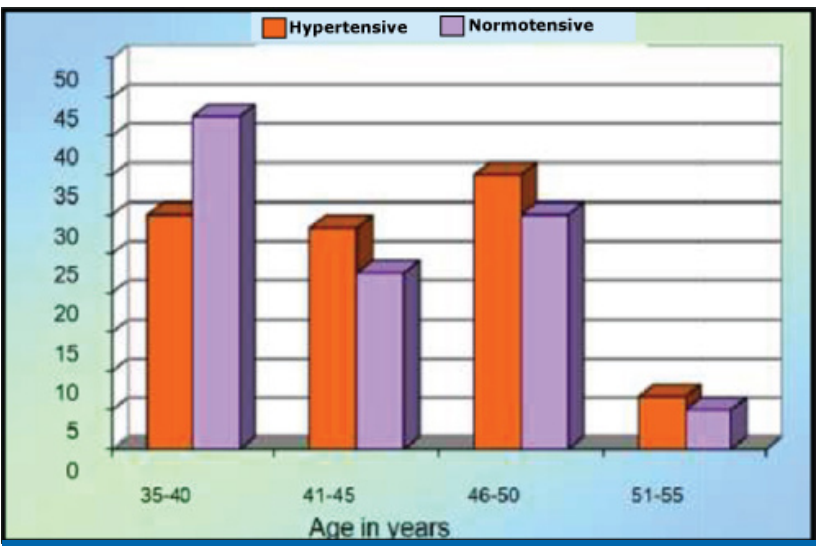

[Table/Fig-3]: Age distribution of normotensives and hypertensives $(n=100)$.

\begin{tabular}{|c|c|c|c|}
\hline M-IMT & Normotensive & Hypertensive & Student t \\
\hline LEFT & $0.49 \pm 0.09$ & $0.97 \pm 0.09$ & $24.560^{* *}$ \\
\hline RIGHT & $0.50 \pm 0.09$ & $0.96 \pm 0.09$ & $25.473^{* *}$ \\
\hline $\begin{array}{c}\text { COMBINED } \\
\text { (Average) }\end{array}$ & $0.50 \pm 0.09$ & $0.97 \pm 0.09$ & $25.859^{* * *}$ \\
\hline
\end{tabular}

[Table/Fig-4]: Shows effect of hypertension on Intima media thickness (IMT).

\begin{tabular}{|c|c|c|c|}
\hline M-RI & Normotensive & Hypertensive & $\begin{array}{c}\text { Mann } \\
\text { Whitney U } \\
\text { test }\end{array}$ \\
\hline LEFT & $0.55 \pm 0.04$ & $0.67 \pm 0.04$ & $\mathrm{P}<0.001^{* *}$ \\
\hline RIGHT & $0.55 \pm 0.03$ & $0.67 \pm 0.04$ & $\mathrm{P}<0.001^{* *}$ \\
\hline
\end{tabular}

[Table/Fig-5]: Shows effect of hypertension on Resistive index (RI).

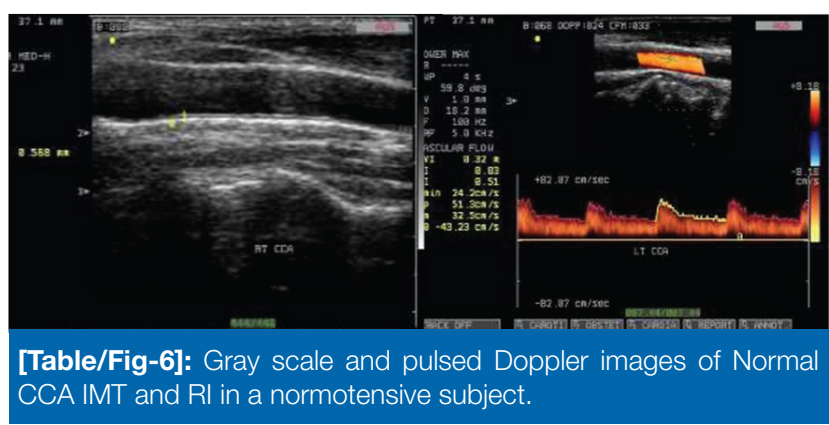

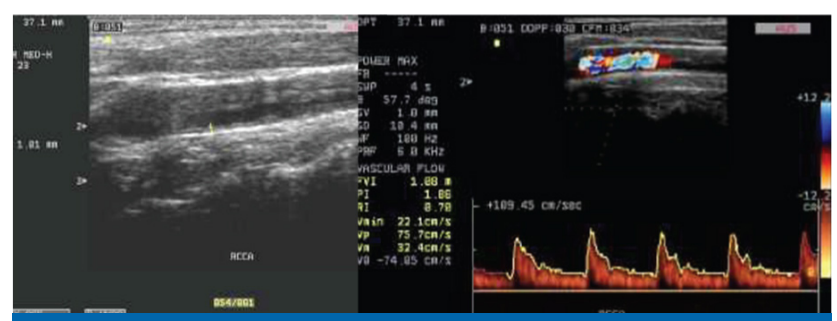

[Table/Fig-7]: Gray scale and pulsed Doppler images of CCA showing increased IMT and RI in hypertensive patient.

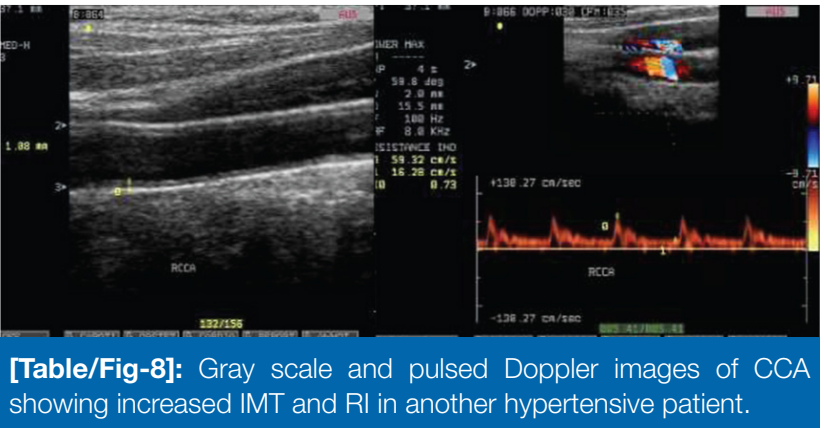

$0.50 \mathrm{~mm}$ in normotensive individuals with mean right and left IMT measuring 0.50 and $0.49 \mathrm{~mm}$ respectively. Mean combined IMT was $0.97 \mathrm{~mm}$ in hypertensive patients with mean right and left IMT measuring 0.96 and $0.97 \mathrm{~mm}$ respectively. Mean $\mathrm{RI}$ was 0.56 in normotensive individuals and 0.67 in hypertensive patients ( $p$-value <0.001).

\section{DISCUSSION}

An increase in the IMT of the carotid arteries measured by ultrasonography is considered to reflect early atherosclerosis. Hypertension has been recognized as a strong risk factor for atherosclerotic cardiovascular diseases. Even isolated systolic hypertension is associated with significant heart failure and cardiovascular mortality [6]. In a Finnish study by Salonen \& Salonen in 1991, for each millimetre increase of Intima media thickness (IMT) the risk of acute coronary event rose 2-14 fold, although the mean follow-up was about one year [7]. Lemne C et al., in 1992 demonstrated increased IMT in hypertensives and their link with cardiovascular diseases [8]. The Rotterdam Study in 1997 established significant relationship between IMT and the risk of cerebrovascular and cardiovascular infarction [9].

Simons PC et al., (SMART study) in 1999 and other similar previous studies demonstrated reduced carotid distensibility along with increased IMT, with increasing severity of atherosclerosis [10]. However, arterial distensibility assessment is a relatively difficult procedure and is subject to significant interobserver and intraobserver variability [11]. Resistive index, a hemodynamic parameter easily determined by Doppler, reflects the vascular resistance. Ishimura et al., demonstrated the correlation between the IMT of the 
CCA and the RI in the renal parenchyma, leading to the possibility that the RI of CCA could be used in assessment of atherosclerosis [12].

Our study showed highly significant (significance at 1\%) relationship between hypertension and IMT and RI values of CCA. The results of our study closely correlate with results of other previous studies [8,13,14]. [Table/Fig-6] shows a normotensive subject with normal IMT and RI.

An Indian study by Adaikkappan M et al., in 2002 yielded similar results as previous studies and concluded that, IMT of CCA is significantly increased in hypertensives when compared to normotensives [15]. Our study results closely correlate with the results of the previous Indian study done by M Adiakappan et al. They studied Intima media thickness [IMT] of total 330 patients out of which 260 were hypertensives and 70 were normotensives. They also studied the associated Doppler parameter changes along with IMT. They concluded that Intima media thickness (IMT) is significantly elevated in hypertensives compared with normotensives. The mean value of Intima media thickness (IMT) in hypertensives was 1.103 with $p$-value of $<0.02$. In our study the mean Intima media thickness (IMT) measurement in hypertensives was 0.97 with $p$-value of $<0.01$. The difference between Resistive index (RI)in hypertensives and normal patients in their study was not significant, whereas in our study the mean value in hypertensives was $0.67 \pm 0.04$ with the $p$-value of $<0.01$ (highly significant).

The major limitation of their study was that the number of controls was significantly smaller compared to the number of cases. [Table/Fig-7,8] shows increased IMT and RI in two different hypertensive patients. Carotid IMT was increased $(0.90 \mathrm{~mm})$ in another Indian study by JM George et al., also, where they compared the carotid IMT values with coronary angiography [16]

Our study was a clinical cross sectional study done on hypertensive and normotensive subjects to know the effect of hypertension on Intima media thickness (IMT) and Resistive index (Rl) of carotid arteries which can be effectively done using high frequency ultrasound and Color Doppler sonography. High frequency ultrasound transducers have made possible, the visualization of the various layers of (intima, media and adventitia) of superficial arteries like carotid arteries, with good resolution. With this, the accurate measurement of Intima media thickness is possible.

Indians have the highest risk of coronary heart disease and it also starts at an early age with higher hospitalization rates [17]. Hence, early identification and aggressive treatment of coronary heart disease is very important to prevent morbidity and mortality. So, the challenge is to implement comprehensive method for identification of initial atherosclerotic events in high risk patients and also in general public so that more vigorous preventive measures can be taken. Coronary calcification, increased arterial wall thickness and elasticity are the non invasive markers for early identification of vessel wall alteration [17-19] Of them, IMT and $\mathrm{RI}$ of CCA are suitable for such examinations since the Doppler sonographic properties of CCA are ideal with lowresistance bed and a highly constant Resistive index [20, 21]. As our study shows that significant changes in IMT and $\mathrm{RI}$ were present in cases with clinical diagnosis of systemic hypertension of duration less than two years, it is definitely possible to use these parameters as screening tools for identifying arterial wall abnormalities. The limitations of our study are smaller sample size and the smaller number of controls than cases.

\section{CONCLUSION}

High-resolution sonography is a simple, safe, quick, accurate and non expensive method of investigation of vessel wall changes in atherosclerosis. IMT gives morphological information and $\mathrm{RI}$ gives hemodynamic information in atherosclerosis of the blood vessels. When both parameters are studied together they are less prone for interobserver and intraobserver variability and will be more accurate. Our study showed that High frequency ultrasound and Color Doppler can be effectively used to study both IMT and RI of CCA together which are significantly increased in hypertensive patients. Our study results closely correlate with the results of previous Indian and Western studies and show that it is ideal to assess both IMT and RI together. Early identification of atherosclerosis using these parameters should prompt early incorporation of lifestyle modification in these patients, which would definitely help in reducing the cardiovascular mortality.

\section{REFERENCES}

[1] Kannel WB. Blood pressure as a cardiovascular risk factor: prevention and treatment. JAMA. 1996; 275: 1571-76.

[2] Palmer AJ, Bulpitt CJ, Fletcher AE, Beevers G, Coles EC, Ledingham JG, et al. Relation between blood pressure and stroke mortality. Stroke. 1992; 20: 601-05.

[3] Poli A, Tremoli E, Colombo A. Ultrasonographic measurement of the common carotid artery wall thickness in hypercholesterolemic patients: a new model for the quantification and follow up of preclinical atherosclerosis in living human subjects. Atherosclerosis.1988; 70:253-61.

[4] Gnasso A, Irace C, Mattioli PL, Pujia A. Carotid intimamedia thickness and coronary heart disease risk factors. Atherosclerosis. 1996; 119:7-15.

[5] Skilton MR, et al. Non invasive measurement of carotid extramedia thickness: associations with cardiovascular risk factors and intima-media thickness. JACC: Cardiovascular Imaging. 2009; 2(2): 176-82.

[6] Ekundayo OJ, Allman RM, Sanders PW, et al. Isolated systolic hypertension and incident heart failure in older adults: a propensity-matched study. Hypertension. 2009;53(3):458-65. 
[7] Salonen R. Salonen JT. Determinants of carotid intima media thickness: a population based ultrasonographic study in eastern finnish men. J Intern med. 1991;116: 225-31.

[8] Lemne C, Jogestrand T, de Faire U. Non invasive assessment of vessel - wall changes in hypertensive and normotensive controls. Clin Physiol. 1992; 12: 497-502.

[9] Bots ML, Hoes AW, Koudstaal PJ, Hofman A, Grobbee DE. Common carotid intima-media thickness and the risk of stroke and myocardial infarction: The rotterdam study. Circulation. 1997; 96: 1432-37.

[10] Simons PC, Algra A, Bots ML, Grobbee DE, van der Graaf Y. Common carotid intima-media thickness and arterial stiffness: indicators of cardiovascular risk in high- risk patients. The SMART Study (Second Manifestations of ARTerial disease). Circulation. 1999; 100:951-57.

[11] Frauchiger $B$, Bock $A$, Eichlisberger $R$, et al. The value of different resistance parameters in distinguishing biopsy-proved dysfunction of renal allografts. Nephrol Dial Transplant. 1995; 10:527-32

[12] Ishimura E, Nishizawa $Y$, Kawagishi T, Okuno Y, Kogawa K, Fukumoto $\mathrm{S}$, et al. Intrarenal hemodynamic abnormalities in diabetic nephropathy measured by duplex Doppler sonography. Kidney Int. 1997; 51:1920-27.

[13] Rauramaa R, Väisänen S, Mercuri M, Rankinen T, Penttilä I and Bond MG. Association of risk factors and body iron status to carotid atherosclerosis in middle-aged Eastern Finnish men. Eur Heart J. 1994; 15:1020-27.

[14] Sun P, Dwyer KM, Merz CNB, Sun W, Johnson CA, Shircore $\mathrm{AM}$ et al. Blood pressure, LDL cholesterol, and intima-media thickness. A test of the "response to injury" hypothesis of atherosclerosis. Arterioscler Thromb Vasc Biol. 2000;20:200510.

[15] Adaikkappan M, Sampath R, FelixAJW, Sethupathy S. Evaluation of carotid atherosclerosis by b'mode ultrasonographic study in hypertensive patients compared with normotensive patients. Ind J Radiol Imag. 2002; 12:3:365-68.

[16] George JM, Bhat R, Pai KM, S. A, Jeganathan J. The carotid intima media thickness: a predictor of the clincal coronary events. Journal of Clinical and Diagnostic Research: JCDR. 2013;7(6):1082-85. doi:10.7860/JCDR/2013/4767.3029.

[17] Reddy KS, Yusuf S. Emerging epidemic of cardiovascular disease in the developing countries. Circulation.1998; 97: 596601.

[18] Su TC, Jeng JS, Chien KL, Torng PL, Sung FC, Lee YT. Measurement reliability of common carotid artery Intima-media thickness by ultrasonographic assessment. J Med Ultrasound. 1999; 7: 73-79.

[19] Jadhav UM, Saraf A, Tanna S. Non-invasive assessment of atherosclerosis. Journal of Preventive Cardiology. 2013; 2 (3): 318-24.

[20] Frauchiger B, Schmid HP, Roedel C, Moosmann P, Staub D. Comparison of carotid arterial resistive indices with IntimaMedia thickness as sonographic markers of Atherosclerosis. Stroke 2001; 32:836-38.

[21] Kasliwal RR, Bansal M, Desai D, Sharma M. Carotid intimamedia thickness: Current evidence, practices, and Indian experience. Indian Journal of Endocrinology and Metabolism. 2014;18(1):13-22.

\section{AUTHOR(S):}

1. Dr. P. Sathish Prabhu

2. Dr. Venkatraman Indiran

3. Dr. Prabakaran Maduraimuthu

\section{PARTICULARS OF CONTRIBUTORS:}

1. Senior Resident, Department of Radiodiagnosis, ESIC Medical College and PGIMSR, Chennai, India.

2. Associate Professor, Department of Radiodiagnosis, Sree Balaji Medical College and Hospital, Chennai, Tamilnadu, India.

3. Professor and Head, Department of Radiodiagnosis, Sree Balaji Medical College and Hospital, Chennai, Tamilnadu, India.

\section{NAME, ADDRESS, E-MAIL ID OF THE CORRESPONDING AUTHOR:}

Dr. Venkatraman Indiran, 32 Kumarapuram, Chromepet, Chennai-600044, India. E-mail: ivraman31@gmail.com

\section{FINANCIAL OR OTHER COMPETING INTERESTS:} None. 